\title{
Risk Factors Associated with False Positive HIV Test Results in a Low-Risk Urban Obstetric Population
}

\author{
Tamara T. Chao, ${ }^{1}$ Jeanne S. Sheffield, ${ }^{1}$ George D. Wendel Jr., ${ }^{1}$ \\ M. Qasim Ansari, ${ }^{2}$ Donald D. McIntire, ${ }^{1}$ and Scott W. Roberts ${ }^{1}$ \\ ${ }^{1}$ Department of Obstetrics and Gynecology, The University of Texas Southwestern Medical Center, Dallas, \\ TX 75390-9032, USA \\ ${ }^{2}$ Department of Pathology, The University of Texas Southwestern Medical Center, Dallas, \\ TX 75390-9032, USA \\ Correspondence should be addressed to Tamara T. Chao, tamaratho@yahoo.com
}

Received 21 April 2011; Accepted 22 June 2011

Academic Editor: Karen Odberg-Petterson

Copyright (C 2012 Tamara T. Chao et al. This is an open access article distributed under the Creative Commons Attribution License, which permits unrestricted use, distribution, and reproduction in any medium, provided the original work is properly cited.

\begin{abstract}
Objective. To examine risk factors for false positive HIV enzyme immunoassay (EIA) testing at delivery. Study Design. A review of pregnant women who delivered at Parkland Hospital between 2005 and 2008 was performed. Patients routinely received serum HIV EIA testing at delivery, with positive results confirmed through immunofluorescent testing. Demographics, HIV, hepatitis B surface antigen (HBsAg), and rapid plasma reagin (RPR) results were obtained. Statistical analyses included Pearson's chi-square and Student's $t$-test. Results. Of 47,794 patients, 47,391 (99\%) tested negative, $145(0.3 \%)$ falsely positive, $172(0.4 \%)$ positive, and $86(0.2 \%)$ equivocal or missing HIV results. The positive predictive value of EIA was $54.3 \%$. Patients with false positive results were more likely nulliparous $(43 \%$ versus $31 \%, P<0.001)$ and younger $(23.9 \pm 5.7$ versus $26.2 \pm 5.9$ years, $P<0.001)$. HIV positive patients were older than false positive patients and more likely positive for HBsAg and RPR. Conclusion. False positive HIV testing at delivery using EIA is associated with young maternal age and nulliparity in this population.
\end{abstract}

\section{Introduction}

The Centers for Disease Control and Prevention (CDC) and United States Preventive Services Task Force (USPSTF) recommend universal HIV screening for all pregnant women entering prenatal care $[1,2]$. This screening enables HIVinfected women and their infants to benefit from appropriate and timely interventions such as antiretroviral medications. When the recommended antiretroviral and obstetric interventions are used, a woman who knows of her HIV infection early in pregnancy now has a less than $2 \%$ chance of delivering an HIV-infected infant. Without intervention, this risk is approximately 25\% in the United States [3-6].

Testing for HIV began in 1985 with the introduction of the enzyme immunoassay (EIA). In order to account for false positive results using screening tests in a low-prevalence population, confirmatory testing has been implemented using a Western blot or immunofluorescence assay. In a lowprevalence population, the false positive rate using the EIA is increased compared to a high-prevalence population, and the positive predictive value of any test will always depend on the prevalence of the condition in the population tested. In testing performed by the CDC, the EIA positive predictive value ranges from 71 to $83 \%$ in populations with HIV prevalence from 0.5 to $1 \%$ [7].

Pregnancy has been observed to be associated with false positive HIV testing. Some investigators believe that the presence of alloantibodies account for the increased false positive rate associated with pregnancy, transfusions, transplantation, and autoimmune diseases [8]. However, risk factors specific to pregnancy that account for this are poorly understood. Conversely, a recent large retrospective study found that the false positive HIV EIA rate was lower in pregnant women compared to nonpregnant individuals 
( $0.14 \%$ versus $0.21 \%)$ [9]. Our objective was to determine if any maternal characteristics correlated with false positive HIV EIA testing at delivery.

\section{Materials and Methods}

This was a review of all women who delivered at Parkland Memorial Hospital in Dallas, Tex, from October 1, 2005 through September 30, 2008. All women routinely received serum HIV testing at their initial prenatal visit and at time of presentation to labor and delivery for delivery via the optout approach with the Abbott Commander HIV AB HIV1/HIV-2 (rDNA) EIA (Abbott Laboratories, Abbott Park, Ill). HIV test results performed at the time of delivery were analyzed in this study. A woman was considered HIV negative if EIA testing was negative. Positive test results were confirmed with the fluorognost immunofluorescent assay (IFA) HIV-1 (Sanochemia Corp, Stamford, Conn, USA). Women were considered to be falsely positive if EIA results were positive and the IFA was negative. Women delivered in this time period were identified through the obstetric operations database and linked to the pathology database for HIV, hepatitis B surface antigen (HBsAg), and rapid plasma reagin (RPR) results. Maternal characteristics, including race, parity, age, singleton versus multiple gestation, and a diagnoses of diabetes or hypertension were obtained using the obstetrics operations database. Laboratory results drawn 28 days prior to delivery through seven days after delivery were included.

The study was approved by the Institutional Review Board at the University of Texas Southwestern Medical Center. Categorical data were reported as frequencies, and statistical significance was determined using $\chi^{2}$ analysis. Two-group comparisons were made using Student's $t$-test. $P$ values less than 0.05 were considered statistically significant. Statistical analyses were performed using SAS, Version 9.2 (SAS Institute, Cary, NC).

\section{Results}

A total of 47,794 women were identified who delivered during the study time frame. Demographic and obstetrical characteristics of the patient population are shown in Table 1. Compared to HIV negative patients, false positive patients were more likely to be nulliparous (43\% versus $31 \%$, $P<0.001$ ) and younger (mean age $23.9 \pm 5.7$ versus $26.2 \pm 5.9$, $P<0.001)$. HIV positive patients were significantly older than false positive patients $(27.4$ versus $23.9, P<0.001)$ and HIV negative patients (27.4 versus $26.2, P=0.012$ ).

Of the 47,794 women, 47,391 (99\%) were HIV negative, $145(0.3 \%)$ had a false positive test, $172(0.4 \%)$ were true positives, and $86(0.2 \%)$ tested equivocal or were missing HIV results. The specificity of the HIV EIA test was $99.7 \%$ with a positive predictive value of $54.3 \%$. The sensitivity of the EIA test was presumed to be near $100 \%$, as the false negative rate using the EIA has been previously demonstrated to be negligible in studies performed by the manufacturer [10].
Table 2 shows the prevalence of diabetes, hypertension, hepatitis B, and results of syphilis testing in the study population. HIV positive women were more likely to test positive for hepatitis B surface antigen (1\% versus $0 \%, P=$ $0.002)$ and $\mathrm{RPR}(2 \%$ versus $0 \%, P=0.02)$. There was no significant difference in the prevalence of diabetes or hypertension between the three groups. There was also no significant difference in the rate of HBsAg and RPR positivity between the HIV negative and false positive groups.

When evaluating the interaction between nulliparity and age, there is a significant correlation between the two variables; that is, parous patients are likely to be older and, therefore, nulliparity and age are not independent predictors of HIV false positivity. However, when the HIV testing groups (positive, false positive, negative) are stratified by parity, the comparison of age across the three groups remains significant only in nulliparous women (Table $3, P=0.0003$ ). The interaction between parity and age means that the difference in age between nulliparous and parous women is different depending on the HIV status. For example, in the HIV positive group the nulliparous and parous women are closer in age than in the false positive group.

\section{Comment}

This was the first population-based study to evaluate risk factors for HIV false positivity in pregnant women presenting for delivery at a large urban institution. We found that younger and nulliparous women were more likely to have false positive testing using the HIV EIA. The observed positive predictive value (PPV) of $54.3 \%$ was lower than the previously reported by the CDC (PPV 71-83\%) in a nonpregnant population [7], suggesting that pregnancy may be associated with a higher rate of false positivity. The low positive predictive value of the HIV EIA in our study may have been impacted by the relatively low HIV prevalence $(0.4 \%)$ in our population. This information could be useful for counseling women who test positive for HIV at delivery and emphasizes the limitations of EIA testing if used as a rapid test to determine the need for intrapartum and neonatal antiretroviral prophylaxis.

The false positive rates of currently available rapid HIV tests have been reported to be much lower than has been found with EIA testing in this study. Tung et al. evaluated the HIV false positive rate in over 900 pregnant women, most of whom were Hispanic, using both the EIA and a rapid pointof-care (POCT) test, OraQuick [11]. They found that while there were no false positive tests with the OraQuick, there were seven false positives using the EIA (PPV 100\% versus $35.7 \%)$. In the Mother-Infant Rapid Intervention at Delivery (MIRIAD) study, Jamieson et al. found that the PPV of the OraQuick test was $90 \%$ while the PPV of the EIA was $74 \%$ $[12,13]$.

Current recommendations by the CDC and the American College of Obstetricians and Gynecologists include rapid HIV screening for women presenting to labor and delivery with undocumented HIV status and for repeat HIV testing in the third trimester for women at high risk or who live in areas 
TABLE 1: Demographic and obstetric characteristics of HIV positive, false positive, and negative women.

\begin{tabular}{|c|c|c|c|c|c|c|}
\hline \multirow[b]{2}{*}{ Characteristic } & \multirow[b]{2}{*}{$\begin{array}{c}\text { Positive } \\
N=172\end{array}$} & \multirow[b]{2}{*}{$\begin{array}{l}\text { False positive } \\
\quad N=145\end{array}$} & \multirow[b]{2}{*}{$\begin{array}{c}\text { Negative } \\
N=47391\end{array}$} & \multicolumn{3}{|c|}{$P$} \\
\hline & & & & $\begin{array}{l}\text { Positive versus } \\
\text { false positive }\end{array}$ & $\begin{array}{c}\text { Positive versus } \\
\text { negative }\end{array}$ & $\begin{array}{c}\text { False positive } \\
\text { versus negative }\end{array}$ \\
\hline Age: mean \pm std & $27.4 \pm 6.2$ & $23.9 \pm 5.7$ & $26.2 \pm 5.9$ & $<0.001$ & 0.012 & $<0.001$ \\
\hline Age & & & & $<0.001$ & 0.021 & 0.002 \\
\hline$<18$ & $2(1)$ & $16(11)$ & $2494(5)$ & & & \\
\hline $18-35$ & $152(88)$ & $124(86)$ & $41412(87)$ & & & \\
\hline$>35$ & $18(10)$ & $5(3)$ & $3485(7)$ & & & \\
\hline Race & & & & $<0.001$ & $<0.001$ & 0.102 \\
\hline Black & $116(67)$ & $19(13)$ & $4422(9)$ & & & \\
\hline White & $16(9)$ & $8(6)$ & $1955(4)$ & & & \\
\hline Hispanic & $38(22)$ & $118(81)$ & $39975(84)$ & & & \\
\hline Other & $2(1)$ & $0(0)$ & $1039(2)$ & & & \\
\hline Nulliparous & $45(26)$ & $63(43)$ & $14488(31)$ & 0.001 & 0.210 & $<0.001$ \\
\hline Parity & & & & 0.002 & 0.009 & 0.004 \\
\hline 0 & $45(26)$ & $63(43)$ & $14488(31)$ & & & \\
\hline 1 & $53(31)$ & $47(32)$ & $14732(31)$ & & & \\
\hline 2 & $35(20)$ & $21(14)$ & $10690(23)$ & & & \\
\hline 3 & $19(11)$ & $9(6)$ & $4893(10)$ & & & \\
\hline$>3$ & $20(12)$ & $5(3)$ & $2588(5)$ & & & \\
\hline Multiple gestation & $1(1)$ & $0(0)$ & $531(1)$ & 0.358 & 0.502 & 0.200 \\
\hline
\end{tabular}

Data expressed as $N(\%)$ or mean \pm standard deviation.

TABLE 2: Comorbidities, hepatitis B, and RPR results in HIV positive, false positive, and negative women.

\begin{tabular}{|c|c|c|c|c|c|c|}
\hline \multirow[b]{2}{*}{ Characteristic } & \multirow{2}{*}{$\begin{array}{c}\text { Positive } \\
N=172\end{array}$} & \multirow{2}{*}{$\begin{array}{l}\text { False positive } \\
\qquad N=145\end{array}$} & \multirow{2}{*}{$\begin{array}{c}\text { Negative } \\
N=47391\end{array}$} & \multicolumn{3}{|c|}{$P$} \\
\hline & & & & $\begin{array}{l}\text { Positive versus } \\
\text { false positive }\end{array}$ & $\begin{array}{c}\text { Positive versus } \\
\text { negative }\end{array}$ & $\begin{array}{c}\text { False positive } \\
\text { versus negative }\end{array}$ \\
\hline Diabetes & $13(8)$ & $8(6)$ & $3015(6)$ & 0.467 & 0.521 & 0.677 \\
\hline Hypertension & $20(12)$ & $16(11)$ & $4164(9)$ & 0.868 & 0.189 & 0.340 \\
\hline HBsAg & & & & 0.002 & $<0.001$ & 0.580 \\
\hline No result & $12(7)$ & $0(0)$ & $224(0.5)$ & & & \\
\hline Negative & $158(92)$ & $145(100)$ & 47038 (99) & & & \\
\hline Positive & $2(1)$ & $0(0)$ & $129(0.3)$ & & & \\
\hline RPR & & & & 0.020 & $<0.001$ & 0.618 \\
\hline No result & $5(3)$ & $0(0)$ & $31(0.07)$ & & & \\
\hline Nonreactive & $163(95)$ & $145(100)$ & 47078 (99) & & & \\
\hline Reactive & $4(2)$ & $0(0)$ & $282(0.6)$ & & & \\
\hline
\end{tabular}

Data expressed as $N(\%)$.

with high HIV prevalence [7, 14, 15]. A woman testing preliminarily positive for HIV in labor should be counseled that she may have HIV infection and that her neonate may be exposed, and immediate antiretroviral prophylaxis should be recommended without waiting for confirmatory test results. The results of our study may aid in counseling women if they test preliminarily positive for HIV using the EIA, while awaiting confirmatory testing results. It remains to be determined whether the same risk factors for false positive HIV EIA testing apply to the POCT tests used in a real life setting.
Our study found that the positive predictive value of EIA testing was only $54.3 \%$ and that younger nulliparous women were more likely to test falsely positive. The reasons for these findings are not entirely clear. Importantly, our data may represent the real world performance of the EIA testing in a large obstetric population-based setting. Investigators also have noted a significant relationship between influenza vaccination and false positive screening for HIV antibodies [1618]. A potential reason for this cross reactivity is that there are similarities in homology between the transmembrane domains of the influenza envelope protein hemagglutinin 
TABLE 3: HIV testing groups stratified by age and parity.

\begin{tabular}{lccc}
\hline \multicolumn{4}{c}{ Nulliparous } \\
\hline \multirow{2}{*}{ HIV result } & $\leq 19$ years & $>19$ years & $P$ \\
& $N=4925$ & $N=9671$ & \\
Positive & $10(0.20)$ & $35(0.36)$ & 0.0003 \\
False positive & $35(0.71)$ & $28(0.29)$ & \\
Negative & $4880(99.1)$ & $9608(99.4)$ & \\
\hline \multicolumn{4}{c}{ Parous } \\
\hline HIV result & $\leq 19$ years & $>19$ years \\
Positive & $N=1568$ & $N=31544$ & \\
False positive & $6(0.45)$ & $120(0.38)$ & 0.5 \\
Negative & $1555(99.2)$ & $31348(99.4)$ & \\
\hline
\end{tabular}

Data expressed as $N(\%)$.

and the HIV-1 envelope proteins [19]. In our population, there were no significant differences in age or parity and influenza vaccination acceptance rates (unpublished data).

There were several limitations to our study. Women in our study were from a single institution, with a predominantly Hispanic background, and therefore the results may not be applicable to all populations. Reasons for false positive HIV serology may vary depending on the geographical region. While we did find a significant association between young age, nulliparity, and HIV false positive testing, our study does not have the capability to identify a causal relationship or explain why this association may exist. In addition, our study cannot address if these same risk factors for false positive testing apply to all other HIV tests. Further studies are needed to confirm our findings, elucidate the biological mechanisms for increased HIV EIA false positivity in young, nulliparous women, and compare this conventional testing method with contemporary rapid screening assays, including POCT.

\section{Acknowledgment}

This work was presented at The Society for Maternal-Fetal Medicine 31st Annual Meeting, February 11, 2011, San Francisco, CA, USA.

\section{References}

[1] Centers for Disease Control and Prevention, "Revised recommendations for HIV testing of adults, adolescents, and pregnant women in health-care settings," Morbidity and Mortality Weekly Report, vol. 55, no. 14, pp. 1-17, 2006.

[2] U.S. Preventive Services Task Force, "Screening for HIV: recommendation statement," AHRQ Publication, no. 07-0597EF-2, March 2011, http://www.uspreventiveservicestaskforce .org/uspstf05/hiv/hivrs.htm.

[3] "Recommendations of the U.S. Public Health Service Task Force on the use of zidovudine to reduce perinatal transimission of human immunodeficiency virus," Morbidity and Mortality Weekly Report, vol. 43, no. 11, pp. 1-20, 1994.
[4] N. A. Wade, G. S. Birkhead, B. L. Warren et al., "Abbreviated regimens of zidovudine prophylaxis and perinatal transmission of the human immunodeficiency virus," New England Journal of Medicine, vol. 339, no. 20, pp. 1409-1414, 1998.

[5] P. M. Garcia, A. Kalish, J. Pitt et al., "Maternal levels of plasma immunodeficiency virus type 1 RNA and the risk of perinatal transmission," New England Journal of Medicine, vol. 341, pp. 394-402, 1999.

[6] L. M. Mofenson, J. S. Lambert, E. R. Stiehm et al., "Risk factors for perinatal transmission of human immunodeficiency virus type 1 in women treated with zidovudine," New England Journal of Medicine, vol. 341, no. 6, pp. 385-393, 1999.

[7] Centers for Disease Control and Prevention, "Rapid HIV1 antibody testing during labor and delivery for women of unknown HIV status: a practical guide and model protocol," November 2010, http://www.cdc.gov/hiv/topics/testing/ resources/guidelines/rt-labor\&delivery.htm.

[8] T. I. Doran and E. Parra, "False-positive and indeterminate human immunodeficiency virus test results in pregnant women," Archives of Family Medicine, vol. 9, no. 9, pp. 924929, 2000.

[9] L. G. Wesolowski, K. P. Delaney, M. A. Lampe, and S. R. Nesheim, "False-positive human immunodeficiency virus enzyme immunoassay results in pregnant women," PLoS ONE, vol. 6, no. 1, Article ID e16538, 2011.

[10] Abbott Laboratories HIVAB ${ }^{\mathrm{TM}}$ HIV-1/HIV-2 (rDNA) EIA, March 2011, http://www.fda.gov/downloads/BiologicsBloodVaccines/SafetyAvailability/TissueSafety/ucm095983.pdf.

[11] C. S. Tung, H. Sangi-Haghpeykar, and J. Levison, "Rapid versus standard testing for prenatal HIV screening in a predominantly Hispanic population," Journal of Perinatology, vol. 30, no. 1, pp. 30-32, 2010.

[12] D. J. Jamieson, M. H. Cohen, R. Maupin et al., "Rapid human immunodeficiency virus-1 testing on labor and delivery in 17 US hospitals: the MIRIAD experience," American Journal of Obstetrics and Gynecology, vol. 197, no. 3, supplement, pp. S72-S82, 2007.

[13] M. Bulterys, D. J. Jamieson, M. J. O’Sullivan et al., "Rapid HIV-1 testing during labor: a multicenter study," Journal of the American Medical Association, vol. 292, no. 2, pp. 219-223, 2004.

[14] B. M. Branson, H. H. Handsfield, M. A. Lampe et al., "Revised recommendations for HIV testing of adults, adolescents, and pregnant women in health-care settings," Morbidity and Mortality Weekly Report, vol. 55, no. 14, pp. 1-17, 2006.

[15] American College of Obstetricians and Gynecologists, "Prenatal and perinatal human immunodeficiency virus testing: expanded recommendations," Committee Opinion, no. 418, September 2008.

[16] W. R. Mac Kenzie, J. P. Davis, D. E. Peterson, A. J. Hibbard, G. Becker, and B. S. Zarvan, "Multiple false-positive serologic tests for HIV, HTLV-1, and hepatitis C following influenza vaccination, 1991," Journal of the American Medical Association, vol. 268, no. 8, pp. 1015-1017, 1992.

[17] L. Simonsen, J. Buffington, C. N. Shapiro et al., "Multiple false reactions in viral antibody screening assays after influenza vaccination," American Journal of Epidemiology, vol. 141, no. 11, pp. 1089-1096, 1995.

[18] C. P. Erickson, T. McNiff, and J. D. Klausner, "Influenza vaccination and false positive HIV results," New England Journal of Medicine, vol. 354, no. 13, pp. 1422-1423, 2006.

[19] D. C. Chan, D. Fass, J. M. Berger, and P. S. Kim, "Core structure of gp41 from the HIV envelope glycoprotein," Cell, vol. 89, no. 2, pp. 263-273, 1997. 


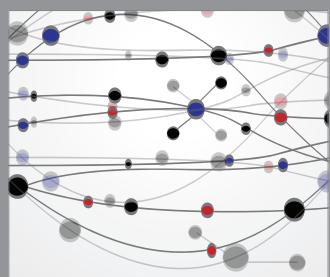

The Scientific World Journal
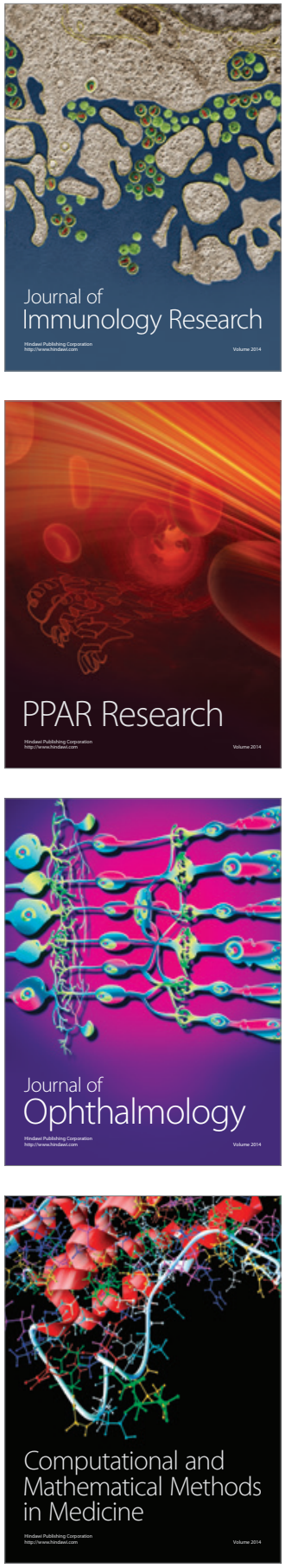

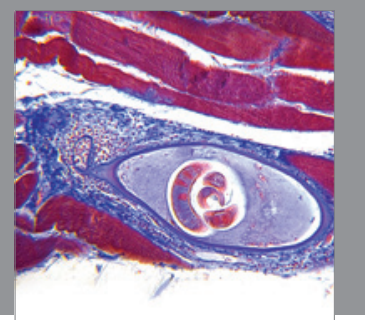

Gastroenterology

Research and Practice
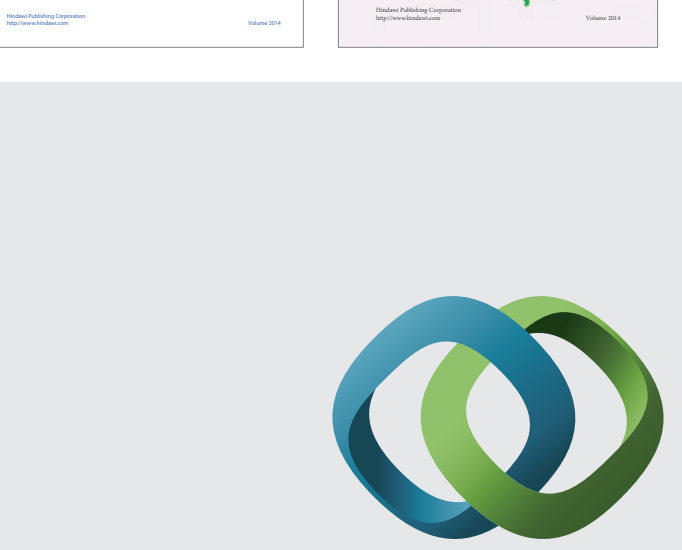

\section{Hindawi}

Submit your manuscripts at

http://www.hindawi.com
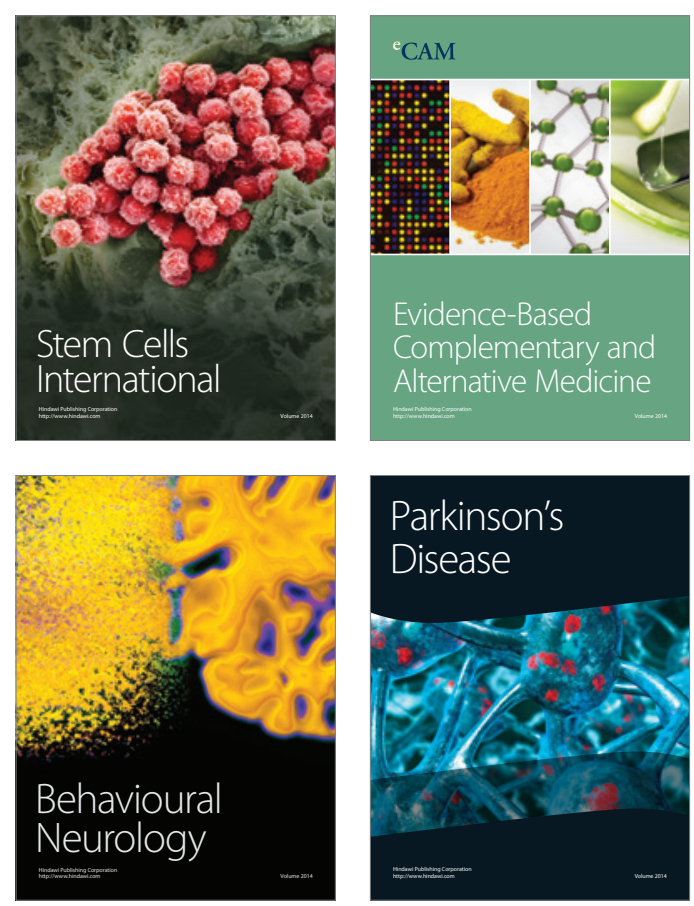

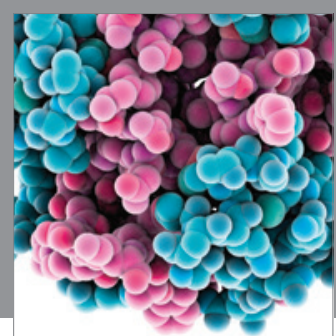

Journal of
Diabetes Research

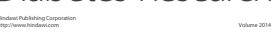

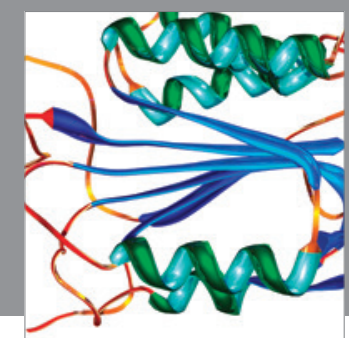

Disease Markers
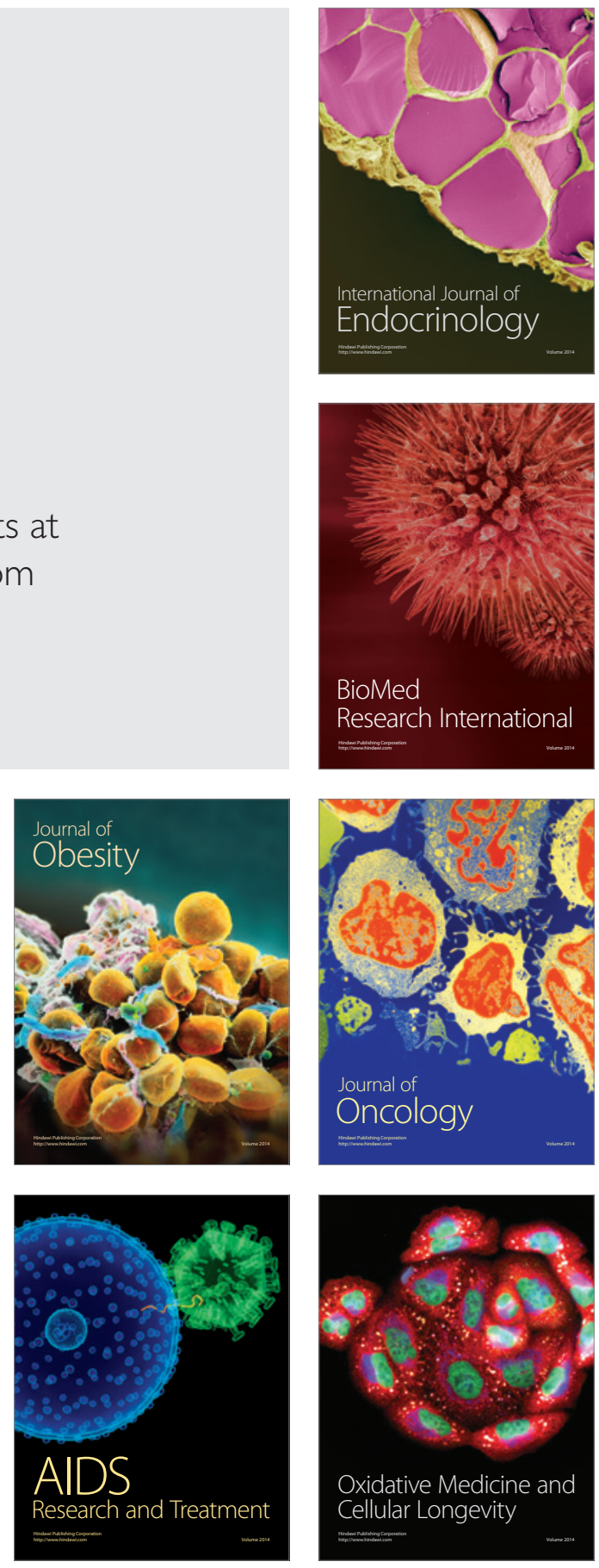